ARTIGOS

\title{
OPORTUNIDADE OU NECESSIDADE? UM ESTUDO DO IMPACTO DO EMPREENDEDORISMO NO DESENVOLVIMENTO ECONÔMICO
}

\section{RESUMO}

Este artigo aborda a importância do empreendedorismo para o crescimento e desenvolvimento econômico, à luz da motivação para se iniciar um negócio: se por necessidade ou por oportunidade. Nesse contexto, no quadro teórico são apresentados os conceitos de empreendedorismo, desenvolvimento econômico e a relação entre estes fenômenos. As variáveis utilizadas nesse estudo foram a razão entre as taxas de empreendedorismo por oportunidade e por necessidade divulgadas pelo Global Entrepreneurship Monitor (GEM) e o Índice de Desenvolvimento Humano (IDH) divulgado pelo Programa das Nações Unidas para o Desenvolvimento (PNUD). Os dados foram coletados nos relatórios da pesquisa GEM e no Relatório de Desenvolvimento Humano (RDH). O período estudado foi do ano de 2006 a 2010. A análise de regressão simples foi utilizada para aferir o comportamento entre as duas variáveis. Os resultados indicaram que existe uma relação positiva moderada entre as duas variáveis e que o empreendedorismo por oportunidade é mais benéfico para o desenvolvimento econômico dos países, embora o empreendedorismo por necessidade tenha sua relevância como alternativa para o desemprego.

Palavras-chave: Empreendedorismo. Oportunidade. Necessidade. Desenvolvimento Econômico.

Estevão Lima de

Carvalho Rocha

Mestre em Administração

- UECE e Pró-Reitor da

Unichristus - Fortaleza-CE-

BR<estevao.lcr@gmail.

com>

\section{INTRODUÇÃO}

$\mathrm{O}$ empreendedorismo tem sido apontado como vetor de geração de emprego e renda (PINTO; RUPPENTHAL, 2014). Embora existam controvérsias, a inerente abertura de novos negócios tem sido considerada positiva para o desen- 
volvimento econômico em diversos países e regiões (MARTES, 2010; DEGEN, 2009; VALE; WILKINSON; AMÂNCIO, 2008; TANG; KOVEOS, 2004; DORNELAS; TIMMONS; SPINELLE, 2010; ROCHA et al., 2011). Por esta sua contribuição para o desenvolvimento, estudos sobre o tema têm despertado interesse por parte de pesquisadores, órgãos governamentais, municípios, estados e países. Entretanto, desde as primeiras citações na literatura, com Richard Cantillon nos anos 1750, o conceito de empreendedorismo vem evoluindo, ampliando o escopo das pesquisas sobre o tema de acordo com a abordagem predeterminada pelos pesquisadores (FILLION, 1999; SOUZA; LOPEZ JR., 2011).

A abertura de novos negócios tem sido indicada como um eixo importante para o direcionamento dos estudos em empreendedorismo (SALIMATH; CULLEN, 2010). Grande parte das abordagens dos estudos tem seguido situações que procuram relacionar as razões que levam o empreendedor a abrir um novo negócio. Nessa perspectiva, Bratu, Cornescu e Druica (2009) apresentam abordagem para o estudo do empreendedorismo a partir de uma tríade de definição: a ocupacional, a comportamental e a de resultados. Na ocupacional os autores a classificaram em necessidade ou oportunidade. Na segunda abordagem, o empreendedor é estudado como o personagem principal que apresenta diferentes concepções na forma como percebe, age e cria novos negócios. A terceira abordagem ampara-se nos diferentes resultados causados pelo empreendedorismo no desenvolvimento econômico.

$\mathrm{Na}$ literatura encontram-se teorias e experimentos empíricos que pretendem explicar quais fatores são determinantes para a ocorrência do empreendedorismo, de forma que se tenha uma relação positiva com o desenvolvimento econômico (CARREE; THURIK, 2003; ACS, 2006; FONTENELE, 2010). Por um lado, existe um consenso de que a vasta abrangência do fenômeno do empreendedorismo exige uma gama de estudos necessários no intuito de interpretar os múltiplos paradigmas que o compõem (SHANE; VENKATARAMAN, 2000). Por outro lado, o enfoque delineado em certas pesquisas poderá, ao se somarem com demais estudos, montar um mosaico teórico que, ao se encaixarem, poderão desenhar uma estrutura teórica para o empreendedorismo (MURPHY; LIAO; WELS$\mathrm{CH}, 2006)$.

Por terem impactos diferentes, alguns estudos na literatura procuram avaliar o papel do empreendedorismo, quando motivado por oportunidade e por necessidade no desenvolvimento econômico dos países (ACS, 2006). Bratu, Cornescu e Druica (2009) apresentam um trabalho em que se encontram os efeitos do empreendedorismo por oportunidade e necessidade no desenvolvimento dos países. Utilizando os dados da pesquisa GLOBAL ENTREPRENEURSHIP MONITOR (2010), estes autores encontraram um efeito positivo para a motivação por oportunidade e, no caso da necessidade, nenhum efeito significativo foi encontrado. O empreendedorismo por oportunidade tem sido visto como de melhor resultado para o desenvolvimento das nações, uma vez que existe uma alta relação com a inovação na ação empreendedora (DEGEN, 2009; HISRICH; PETERS; SHEPHERD, 2009; ACS 2006).

$\mathrm{O}$ apregoado efeito positivo causado no desenvolvimento econômico tende a favorecer o empreendedorismo por oportunidade. A maioria das nações tem perseguido um desenvolvimento que se traduza em 
melhorar a qualidade de vida das pessoas, juntamente com o crescimento econômico. Atualmente, na literatura, pesquisadores têm utilizado o conceito de desenvolvimento como aquele que gera crescimento e agrega melhores condições de vida para a população (SOUZA; LOPEZ JR., 2011; OLIVEIRA, 2002). O Produto Interno Bruto (PIB) per capita tem sido usado como variável indicadora do desenvolvimento econômico dos países em diversas pesquisas (FONTENELE, 2010; BARROS; PEREIRA, 2008; CARREE; THURIK, 2003). No entanto, como forma de integrar o conceito de desenvolvimento e qualidade de vida, neste trabalho optou-se por utilizar o Índice de Desenvolvimento Humano (IDH) como variável representante do desenvolvimento econômico (BRATU; CORNESCU, V.; DRUICA, 2009).

Acs (2006) e Bratu, Cornescu e Druica (2009) apontam em seus respectivos estudos que existe uma significativa relação positiva entre empreendedorismo por oportunidade e desenvolvimento econômico. $\mathrm{O}$ presente estudo pretende avaliar o efeito do empreendedorismo por oportunidade em relação ao de necessidade na variável IDH dos países integrantes da pesquisa GEM no período de 2006 até 2010. Logo, a indagação que se coloca a partir da constatação dos estudos destes autores é a seguinte: $\mathrm{O}$ aumento de empreendedores motivados por oportunidade e a diminuição dos motivados por necessidade eleva o nível de desenvolvimento econômico dos países?

Diante desse questionamento, o objetivo neste estudo foi comparar e analisar as taxas de empreendedorismo dos países com seus respectivos IDH catalogados ano a ano. Partindo da base teórico-empírica, que se assenta no conceito e relação entre empreendedorismo e desenvolvimento econômico, o artigo segue com a metodologia utilizada na investigação, depois com a análise e discussão dos resultados, seguidos das considerações finais. A relevância desse estudo fundamenta-se em possibilitar o entendimento dos efeitos de tipos diferentes de empreendedorismo na economia dos países, contribuindo com informações que auxiliem a interpretação desse fenômeno econômico-social.

\section{REFERENCIAL TEÓRICO}

\subsection{EMPREENDEDORISMO}

A origem do tema empreendedorismo pode ser considerada a partir das obras de Cantillon em 1755 e Say em 1803. O viés econômico abordado desde este início tem situado o empreendedorismo entre um dos fatores que induzem o desenvolvimento econômico de regiões e países (FILLION, 1999; MURPHY; LIAO; WELSCH, 2006; CASSON, 2010). Diversos estudos vêm sendo desenvolvidos, em que se trata a correlação entre estes dois fenômenos. A importância dada ao empreendedorismo decorre da criação de empregos e geração de riqueza produzida pela ação de sujeitos que agem em função de oportunidades, riscos e determinação em busca de resultados lucrativos que garantam seu bem viver (SCHUMPETER, 1982; CASSON, 1982; SHANE; VENKATARAMAN, 2000; HISRICH; PETERS; SHEPHERD, 2009; DEGEN, 2009; MARTES, 2010).

A ação empreendedora vai além de se criar novas empresas. Diversos autores a interpretam de forma que as inovações que se transformam em oportunidades podem ser aplicadas em negócios já existentes, criando-se um novo modelo de produto ou ser- 
viço, gerando-se novas receitas ou custos menores para a firma (ACS; STORY, 2004; DORNELAS; TIMMONS; SPINELLE, 2010). Entretanto, a relação entre empreendedorismo e desenvolvimento econômico tem sido avaliada empiricamente por diversas pesquisas em que se associam a criação de novos negócios como fonte geradora de emprego e renda (SALIMATH; CULLEN, 2010). Embora nem sempre exista relação positiva entre aberturas de novas empresas e crescimento econômico (TANG; KOVEOS, 2004), o empreendedorismo tem sido creditado como importante matriz indutora do crescimento econômico.

Entre os grupos de pesquisa nessa área, o programa de pesquisa GEM tem se destacado por realizar estudos e com- parações das taxas de empreendedorismo e a economia entre diversos países desde 1999. Inicialmente com 10 países, o estudo ampliou para cerca de 80 no ano de 2010. Nesse programa, a pesquisa GEM tem como principais objetivos medir a diferença entre o nível de empreendedorismo entre os países, descobrir os fatores que limitam e favorecem a atividade empreendedora e identificar as políticas públicas que podem favorecer o empreendedorismo nos países pesquisados (GLOBAL ENTREPRENEURSHIP MONITOR, 2010). A pesquisa GEM trabalha com três principais taxas que são utilizadas para comparar as atividades empreendedoras entre os países. O quadro 1 apresenta estas taxas e suas descrições.

\begin{tabular}{l|l}
\hline \multicolumn{1}{c|}{ TAXA } & \multicolumn{1}{c}{ DESCRIÇÃO } \\
\hline $\begin{array}{l}\text { Taxa de Empreendedorismo em } \\
\text { Estágio Inicial (TEA) }\end{array}$ & $\begin{array}{l}\text { A proporção de pessoas na faixa etária entre 18 e 64 anos envolvidas } \\
\text { em atividades empreendedoras. }\end{array}$ \\
\hline $\begin{array}{l}\text { Taxa de Empreendedorismo } \\
\text { por Necessidade }\end{array}$ & $\begin{array}{l}\text { A proporção de empreendedores da taxa TEA que estão envolvidos } \\
\text { com empreendedorismo por não ter outra opção de trabalho. }\end{array}$ \\
\hline $\begin{array}{l}\text { Taxa de Empreendedorismo } \\
\text { por Oportunidade }\end{array}$ & $\begin{array}{l}\text { A proporção de empreendedores da taxa TEA que estão envolvidos } \\
\text { com empreendedorismo por ter identificado uma oportunidade de } \\
\text { negócio que desejou perseguir. }\end{array}$ \\
\hline
\end{tabular}

Quadro 1- Taxas de atividades empreendedoras

Fonte: Relatório Global Entrepreneurship Monitor (2010)

Os procedimentos e instrumentos de pesquisa são padronizados para todos os países participantes. A coleta de dados para avaliar o nível da atividade empreendedora e a motivação (se por oportunidade ou por necessidade) é realizada por meio de entrevistas e aplicação de questionários entre os empreendedores identificados. Encontra-se na literatura que a associação da inovação com a oportunidade nem sempre tem sido adotada como premissa entre os empreendedores. Muitos deles têm iniciado o ne- gócio em função de uma necessidade, normalmente causada devido ao desemprego (BRATU; CORNESCU; DRUICA, 2009; CORRÊA; VALE, 2013). Pesquisas sustentadas por resultados empíricos têm revelado que, embora tenha existido aumento da taxa de empreendedorismo em alguns países, o crescimento econômico medido pelo PIB per capita apresentou diminuição em comparação ao ano anterior (FONTENELE, 2010; SOUZA; LOPEZ JR., 2011). A causa apontada tem sido um aumento da 
taxa de empreendedores por necessidade em decorrência do desemprego. A renda auferida por estes novos empreendedores, em muitos casos, tem sido inferior aos antigos salários que possuíam (SALIMATH; CULLEN, 2010; ACS, 2006; TANG; KOVEOS, 2004).

Estudiosos do modelo do empreendedor schumptariano têm defendido o binômio inovação e oportunidade como característica fundamental para o sucesso da ação empreendedora no desenvolvimento econômico (MARTES, 2010; BRATU; CORNESCU; DRUICA, 2009; CASSON, 1982; SHANE; VENKATARAMAN, 2000). Para Schumpeter (1982), desenvolvimento se diferencia de crescimento econômico, no ponto em que este se refere à adaptação e ao mero aumento de capital, e aquele se refere às mudanças, desequilíbrios e aumento do volume de riquezas. Dito dessa forma, $o$ autor associa $o$ ato de empreender ao desenvolvimento econômico. As inovações criadas provocam a destruição de antigos padrões, ocupando novos espaços no mercado e impulsionando o motor do desenvolvimento.

\subsection{CARACTERÍSTICAS DO EMPRE- ENDEDORISMO POR NECESSIDADE E POR OPORTUNIDADE}

O empreendedorismo por necessidade tem sido associado às condições de queda de atividade econômica que gera desemprego e diminui a oferta de emprego. A ocorrência desse cenário tem impulsionado pessoas a iniciarem uma atividade econômica que possibilite sua sobrevivência econômica (CORRÊA; VALE, 2013; DOMINGUINHOS; PEREIRA; SILVEIRA, 2007). No entanto, a entrada forçada em uma ati- vidade própria pode resultar em maiores probabilidades de fracasso, em função da falta de planejamento adequado, não gerando o esperado desenvolvimento econômico (DORNELAS, 2008).

Embora a abertura de novas empresas enquadre-se como atividade empreendedora no escopo geral do empreendedorismo, alguns autores vêm questionando a inclusão de empresas originadas por necessidade. Carrão, Johnson e Montebelo (2007) argumentam que, em vários casos, a falta de opção de trabalho tem sido a motivação para se criar uma empresa, caracterizando-se de autoemprego o empreendimento criado compulsoriamente como forma de garantir a sobrevivência. Para estes autores, sob tais circunstâncias, os criadores dessas empresas não poderiam ser categorizados como empreendedores, uma vez que esta condição lhes foi imposta. Berlung e Johansson (2007) afirmam que, nas diferentes concepções de pesquisas sobre empreendedorismo, o ponto em comum encontrado tem sido a capacidade humana de criar coisas novas. Estes autores argumentam que o fato de se abrir um novo negócio copiando um já existente, como forma de sobrevivência, poria em dúvida a caracterização como um ato empreendedor.

Por sua vez, o empreendedorismo por oportunidade tem sido defendido por diversos autores como o tipo mais representativo do empreendedor shumpeteriano. A capacidade de inovar, criando novas oportunidades de exploração comercial, tem sido apontada como a essência da ação empreendedora (VALE; WILKINSON; AMÂNCIO, 2008; CUNHA et al., 2009; FOO, 2009). Embora se percebendo uma oportunidade para abrir uma empresa, o simples fato de abrir esta empresa não pode ser categorizado, de imediato, como ato empreendedor. $\mathrm{O}$ ter- 
mo "oportunidade", associado ao empreendedorismo, implica em processo criativo de novas concepções que alteram a forma tradicional até então utilizada no respectivo segmento econômico (FERNADES; SANTOS, 2008; MACIEL, 2009; SHANE; VENKATARAMAM, 2000).

No contexto do empreendedorismo, para Hisrich, Peters e Shedherd (2009), a oportunidade de negócio é representada por uma possibilidade de o empreendedor atender com sucesso a uma necessidade "insatisfeita suficientemente grande", resultando em vendas e lucros. Dornelas, Timmons e Spinelle (2010) acrescentam que a oportunidade pode surgir a partir de tendências e comportamentos dos consumidores em busca de novos produtos ou serviços. O empreendedor opera de forma a lançar as novas propostas no momento adequado, de forma que seja agregado valor para o usuário final do serviço ou produto.

Segundo Luecke (2009), nas economias de livre mercado, janelas de oportunidades para empreendimentos rentáveis sempre tendem a aparecer. Este autor apresenta cinco situações ou áreas em que se poderiam encontrar estas janelas de oportunidades:

a) novos conhecimentos e mudança tecnológica;

b) mudanças na regulamentação;

c) turbilhão social e colapso civil;

d) mudança nos gostos;

e) a busca por soluções convenientes.

A conjugação da criatividade, inovação e oportunidade tem sido o modus operandi do empreendedor mais associado ao definido por Schumpeter (1982). As alterações introduzidas no mercado por estes empreendedores têm movimentado a economia, gerando crescimento e desenvolvi- mento econômico (VALE; WILKINSON; AMÂNCIO, 2008; FONTENELE，2010; SOUZA; LOPEZ JR., 2011).

\subsection{EMPREENDEDORISMO E DESEN- VOLVIMENTO ECONÔMICO}

A geração de emprego e renda advindos do processo empreendedor, em função de sua caracterização de abertura de novos negócios, tem sido postulada como força indutora de crescimento econômico (PINTO; RUPPENTHAL, 2014; SARFATI, 2013). Por outro lado, o aumento quantitativo de produção e renda per capita, que envolve a medição deste crescimento, não tem sido considerado suficiente para determinar os impactos econômicos e sociais que podem ser proporcionados pelo empreendedorismo (SOUZA; LOPES JR., 2011). Seguindo o pensamento de Schumpeter (1982), Hisrich, Peter e Shepherd (2009), Degen (2009), Fontenele, Moura e Leocadio (2011) arguem que a ação empreendedora realizada pela sequência criatividade, inovação, oportunidade e lucro vai além do conceito de crescimento. O ciclo econômico ocasionado pelo empreendedorismo, afirmam, gera tanto o crescimento quanto o desenvolvimento econômico e social das nações.

Embora existam debates no meio acadêmico sobre a distinção entre crescimento e desenvolvimento econômico, este presente trabalho tem considerado a definição de desenvolvimento como aquele que proporciona melhorias na qualidade de vida da população em geral (OLIVEIRA, 2002). Dessa forma, enquanto o crescimento pode ser medido por meio da evolução do PIB per capita, o desenvolvimento pode ser medido por um índice que alcance maior abrangên- 
cia social no âmbito das populações avaliadas. Segundo Machado e Pamplona (2008), o IDH, proposto pelo Programa das Nações Unidas para o Desenvolvimento (PNUD), tem sido adotado pela Organização das Nações Unidas (ONU) com este objetivo.

Em 1990, O PNUD passou a emitir o Relatório de Desenvolvimento Humano (RDH), com o recém-criado IDH. Este, por sua vez, tem a premissa de medir o desenvolvimento das nações, acrescentando-se elementos de ênfase mais social, conforme RDH de 2010 (BRASIL, 2010). Desse modo, o IDH tem tido como objetivo captar o paradigma do desenvolvimento humano a partir do contexto do crescimento econômico associado ao desenvolvimento social. O IDH é composto por três elementos essenciais:

a) longevidade (expectativa de vida ao nascer);

b) conhecimento (taxa de alfabetização e média dos anos de escolaridade);

c) padrão de vida (PIB per capita, ajustado pela Paridade do Poder de Compra) (MACHADO; PAMPLONA, 2008).
Nos estudos entre empreendedorismo e desenvolvimento econômico, o empreendedorismo por necessidade tem estado mais presente como atividade empreendedora em países menos desenvolvidos frente aos mais desenvolvidos (BRATU; CORNESCU; DRUICA, 2009; BARROS; PEREIRA, 2008). Avaliar o papel dos dois tipos de motivação que levam a se iniciar uma atividade empreendedora tem sido objeto de estudo por vários autores. Acs (2006) realizou um estudo de análise de regressão utilizando a razão entre empreendedorismo por oportunidade e por necessidade, a fim de estimar a influência do volume do empreendedorismo por oportunidade no desenvolvimento econômico dos países da pesquisa GEM 2004. O autor defende que a vantagem dessa sequência de classificação (a razão entre as taxas) reside no fato de países com altos níveis de empreendedorismo por necessidade poderem ser "ranqueados" da mesma forma que os de baixo nível de empreendedorismo. O quadro 2 apresenta um exemplo de dois países para esclarecer a proposição do autor.

\begin{tabular}{|c|c|c|c|c|}
\hline \multirow{2}{*}{ Países } & \multicolumn{3}{|c|}{ Taxas de emprendorismo ano 2010} & \multirow{2}{*}{ Razão } \\
\cline { 2 - 4 } & TEA & Oportunidade & Necessidade & \\
\hline Angola & $31,9 \%$ & $19,9 \%$ & $11,4 \%$ & 1,74 \\
\hline Noruega & $7,7 \%$ & $6,3 \%$ & $1,2 \%$ & 5,25 \\
\hline
\end{tabular}

Quadro 2 - Demonstrativo de taxa e razão de empreendedorismo por oportunidade e necessidade Fonte: Relatório Global Entrepreneurship Monitor (2010)

Com o exemplo dos países Angola e Noruega, é possível perceber que, embora Angola apresente taxas de empreendedorismo bem maiores, a Noruega apresenta razão mais elevada entre a taxa de empreendedorismo por oportunidade versus a por necessidade. Acs (2006) encontrou em sua pesquisa uma relação positiva entre maior presença de empreendedorismo por oportunidade e o PIB per capita. Com esse resultado, o autor confirmou a existência de correlação positiva entre o empreendedorismo por oportunidade e o desenvolvimento econômico entre os países da pesquisa GEM 2004. 
Nesse contexto, avaliar a diferença que tem o papel dos dois tipos de empreendedorismo no desenvolvimento econômico dos países pode ser considerado importante. A partir dos resultados dos estudos, os investimentos públicos podem ser direcionados para a construção de um ambiente que favoreça o surgimento de mais empreendedores com o perfil favorável ao desenvolvimento. Nessa perspectiva, este trabalho procurou alinhar uma nova variável mais abrangente de desenvolvimento econômico com o estudo do impacto do volume do empreendedorismo por oportunidade nesse desenvolvimento. Assim, com o propósito de responder a questão posta nesta pesquisa, foi formulada a seguinte hipótese:

H1: Uma maior razão entre empreendedorismo por oportunidade e por necessidade influencia positivamente o IDH dos países.

\section{METODOLOGIA}

Este estudo pode ser classificado como quantitativo, de caráter exploratório e descritivo, baseado em conjunto de dados longitudinais (HAIR et al., 2005; VERGARA, 2009), tendo como intenção investigar a influência do empreendedorismo no Índice de Desenvolvimento Humano (IDH). Os dados foram coletados no Relatório GEM de 2006 a 2010 e no Relatório do Desenvolvimento Humano (RDH) de 2006 a 2010. As comparações entre as taxas de empreendedorismo por oportunidade e por necessidade e IDH ocorreram no lapso temporal de 5 anos. A população desta pesquisa foi composta por um grupo de 83 países relacionados nos relatórios GEM especificados. Os países de cada série anual, com os correspondentes IDH disponíveis, foram considerados como a amostra desta pesquisa. A coleta de dados procedeu-se por meio das respectivas informações dos países de cada série anual. Desse modo, com o aumento de países participantes a cada ano, foram obtidos 238 registros. O Quadro 3 apresenta a relação de países que fizeram parte deste trabalho.

\begin{tabular}{|c|c|c|c|c|}
\hline África do Sul & Colômbia & Holanda & Malásia & Romênia \\
\hline Alemanha & Coréia do Sul & Hong Kong & Marrocos & Rússia \\
\hline Angola & Costa Rica & Hungria & México & Sérvia \\
\hline Arábia Saudita & Croácia & Iêmen & Montenegro & Śria \\
\hline Argélia & Dinamarca & Índia & Noruega & Suécia \\
\hline Argentina & Egito & Indonésia & Nova Zelândia & Suíça \\
\hline Austrália & Emirados Árabes & Irã & Palestina & Tailândia \\
\hline Áustria & Equador & Irlanda & Panamá & Tonga \\
\hline Bélgica & Eslovênia & Islândia & Paquistão & Trinidad e Tobago \\
\hline Bolívia & Espanha & Israel & Peru & Tunísia \\
\hline Bósnia & Estados Unidos & Itália & Polônia & Turquia \\
\hline Brasil & Filipinas & Jamaica & Porto Rico & Uganda \\
\hline Canadá & Finlândia & Japão & Portugal & Uruguai \\
\hline Cazaquistão & França & Jordânia & Reino Unido & Vanuatu \\
\hline Chile & Gana & Letônia & Rep. Dominicana & Venezuela \\
\hline China & Grécia & Líbano & Rep. Tcheca & Zâmbia \\
\hline Cingapura & Guatemala & Macedônia & & \\
\hline
\end{tabular}

Quadro 3 - Países integrantes da pesquisa

Fonte: elaborado com base nos países participantes da pesquisa GEM de 2006 a 2010 (GLOBAL ENTREPRENEURSHIP MONITOR, 2010). 
Para o objetivo de responder a investigação da questão desta pesquisa, foram definidas duas variáveis: razão entre empreendedorismo por oportunidade e por necessidade (RON) e índice de desenvolvimento humano (IDH). A razão entre as duas motivações de empreendedorismo foi calculada a partir das taxas respectivas de cada país, utilizando-se a seguinte fórmula:

\section{$\mathrm{RON}=\underline{\text { Taxa de empreendedorismo por oportunidade }}$ \\ Taxa de empreendedorismo por necessidade}

A variável RON representa a incidência do empreendedorismo por oportunidade em relação ao empreendedorismo por necessidade. Desse modo, quanto maior o valor da variável RON, maior será o empreendedorismo por oportunidade frente ao de necessidade no país pesquisado. A RON foi a variável adotada como independente. O desenvolvimento econômico dos países está representado pela variável dependente IDH.

Os modelos de análise estatística aplicados foram a correlação e a regressão linear simples. Com a análise da correlação de Pearson mediu-se o grau de correlação entre as variáveis e em que direção, negativa ou positiva, deu-se esta correlação. A análise de regressão simples foi utilizada para mensurar as relações lineares entre as variáveis. Desse modo, foi aplicada esta técnica estatística para aferir a magnitude, o tipo de associação e as previsões de mudança, entre a variável independente RON e a variável dependente IDH (HAIR et al., 2005). O software SPSS versão 10.0 foi o instrumento utilizado para processar os dados desta pesquisa.

\section{RESULTADOS E DISCUSSÃO}

$\mathrm{Na}$ etapa inicial da análise dos dados, como primeiro passo, foi calculada a razão RON para todos os países da pesquisa GEM de 2006 a 2010. Foram identificados 86 países e 241 registros. No segundo passo, procurou-se, para os mesmos países e respectivos anos, o IDH correspondente nos relatórios RDH de 2006 a 2010. Com isso, 3 países foram descartados, devido a não terem sido encontrados os respectivos IDH. Dessa forma, participaram deste trabalho 83 diferentes países, resultando na obtenção de 238 registros para as variáveis RON e IDH. A distribuição geográfica dos países deu-se da seguinte forma: África com 20 (24,1\%); América Central com 7 $(8,4 \%)$; América do Norte 3 (3,6\%); América do Sul 9 (10,8\%); Ásia 7 (8,4\%); Europa $31(37,3 \%)$ e; Oceania $6(7,2 \%)$.

$\mathrm{Na}$ etapa seguinte, o procedimento estatístico foi realizado a fim de se avaliar as relações entre as variáveis RON e IDH. Efetuou-se teste estatístico para verificar a correlação entre estas duas variáveis. Foi encontrado um coeficiente de Pearson $\mathrm{r}=$ 0,492, com nível de significância $0,05, \alpha=$ 0,000. De acordo com Hair et al. (2005), estes resultados indicam que a relação entre estas variáveis é significativa, positiva e moderadamente forte. A análise de regressão linear simples deu seguimento ao processo. Com 238 observações, o coeficiente de determinação $\mathrm{R}^{2}$ encontrado foi igual a 0,242 , enquanto o $\mathrm{R}^{2}$ ajustado foi de 0,239 . $\mathrm{O}$ teste $\mathrm{F}$-ANOVA foi aplicado com a fina- 
lidade de verificar se a variável independente, neste trabalho a RON, exerce influência significativa na variável dependente, o IDH (CORRAR; PAULO; DIAS FILHO, 2011). A tabela 1 fornece os resultados deste teste estatístico.

Tabela 1 - Análise da Variância da Regressão Linear Simples das variáveis RON e IDH

\begin{tabular}{l|c|c|c|c}
\hline \multicolumn{1}{c}{ Modelo } & Soma dos quadrados & \multicolumn{1}{c}{ Quadrado médio } & \multicolumn{1}{c}{ S } \\
\hline Regressão & 0,815 & 0,815 & 75,368 & 0,000 \\
Resíduo & 2,551 & 0,011 & & \\
Total & 3,365 & & & \\
\hline
\end{tabular}

Fonte: dados da pesquisa

Os dados da Tabela 1, em que $\mathrm{F}=$ 75,368, com correspondente significância 0,000 , confirmam o $\mathrm{R}^{2}$ significativamente diferente de zero, rejeitando a hipótese nula e indicando que a variável independente RON é significativa para explicar a variável IDH. Com isso, tem-se que $24,2 \%$, ou $23,9 \%$, usando-se o $\mathrm{R}^{2}$ ajustado da variação do Índice de Desenvolvimento $\mathrm{Hu}$ - mano, podem ser explicados, neste estudo, pelas variações ocorridas na razão entre empreendedorismo por oportunidade e por necessidade. $\mathrm{O}$ teste $\mathrm{t}$, com os resultados na Tabela 2, confirmam a significância estatística do coeficiente de regressão. Desse modo, nesse estudo, é possível afirmar que para cada unidade crescente da razão RON, o IDH aumenta 0,015 no índice dos países.

Tabela 2 - Resultados teste $\mathbf{t}$ da regressão linear

\begin{tabular}{c|c|c|c}
\hline \multicolumn{2}{c}{ Variáveis } & Coeficientes & $\mathrm{t}$ \\
\hline Constante & 0,762 & 77,961 & 0,000 \\
Razão RON & 0,015 & 8,681 & 0,000 \\
\hline
\end{tabular}

Fonte: dados da pesquisa

Os resultados encontrados confirmam a hipótese $\mathrm{H} 1$ deste trabalho. A relação positiva entre a variável RON e a variável IDH demonstra o papel positivo que o empreendedorismo por oportunidade tem para promover o desenvolvimento econômico, corroborando com os estudos de Acs (2006). A relação direta apontada entre o empreendedorismo por oportunidade com a criatividade e a inovação pode ser um fator determinante para o desempenho desse tipo de empreendedorismo no desenvolvimento dos países (SHANE; VENKATARAM,
2000). Os resultados também assinalam que altas taxas de empreendedorismo, sobretudo por necessidade, podem ter uma relação inversa com o desenvolvimento econômico, o que pode indicar uma forte migração de desempregados para uma condição de trabalhador autônomo, com rendimento inferior ao antigo emprego (BARROS; PEREIRA, 2008; BONANCIM; CUNHA; CORRÊA, 2009; SALIMATH; CULLEN, 2010).

Fontenele, Moura e Leocádio (2011) argumentam que uma das maiores dificul- 
dades para realizar uma análise empírica da relação entre empreendedorismo e o desenvolvimento de países recai na obtenção de medidas adequadas. As taxas desta pesquisa coletadas das séries temporais da pesquisa GEM, uma vez que, têm sido realizadas com procedimentos técnicos que demonstram consistência, podem ser consideradas de boa medida de proxy para o empreendedorismo. Na mesma dimensão, a coleta do índice do IDH das séries temporais da ONU transmitem consistência, possibilitando a aceitação do IDH como boa medida de proxy para o desenvolvimento econômico.

Desse modo, os resultados empíricos encontrados por esse modelo de regressão indicam que a razão entre empreendedorismo por oportunidade e necessidade pode explicar cerca de $24 \%$ da variação total do IDH dos países. Para cada variação de unidade positiva da razão RON o IDH dos países poderá aumentar em 0,015 . Os resultados sugerem ainda que existem cerca de $76 \%$ da variação do IDH que não são explicados por esse modelo de regressão. Este resultado pode sugerir a leitura do fenômeno do empreendedorismo como um fenômeno multifacetado. Outros fatores precisam ser considerados para uma melhor avaliação do empreendedorismo no desenvolvimento econômico (SOUZA; LOPEZ JR., 2011).

\section{CONSIDERAÇÕES FINAIS}

A relação do empreendedorismo com o desenvolvimento econômico tem sido avaliada por diversos estudos. Embora resultados destoantes tenham aparecido, uma significativa parcela tem encontrado uma relação positiva entre esses dois fenômenos. O empreendedorismo per si não tem garantido o suposto crescimento econômico, quando medido pelo PIB per capita. Acontecimentos socioeconômicos podem influenciar o surgimento de novas empresas, sem, entretanto, gerar crescimento econômico. O fenômeno do desemprego tem sido um dos principais fatores que elevam a taxa de empreendedorismo, sobretudo em países de baixo desenvolvimento. No entanto, sem crescimento econômico, dificilmente aparecerá desenvolvimento econômico na maioria dos países.

$\mathrm{O}$ índice de desenvolvimento $\mathrm{Hu}-$ mano (IDH) carrega em sua composição a componente PIB per capita, justamente a variável responsável em captar o crescimento econômico obtido pelos países anualmente. $\mathrm{O}$ aumento de renda tem sido uma forma direta de proporcionar melhores condições de vida para a população em geral. O empreendedorismo pode ser um instrumento de aumento de renda das nações. $\mathrm{O}$ empreendedorismo por oportunidade tem se caracterizado como aquele que envolve inovação no contexto da criação de oportunidades percebida pelo empreendedor. Esse tipo de ação empreendedora, em que a escolha de abrir o negócio está baseada em uma perspectiva de gerar maiores ganhos, tem gerado maiores crescimento e desenvolvimento para as nações.

Por outro lado, o empreendedorismo por necessidade, apesar de em vários estudos não apontar relação significativa ou até mesmo negativa com o crescimento econômico, tem o seu papel como fonte geradora de emprego e autoemprego. O ciclo econômico de cada país pode passar, em diversas ocasiões, por períodos de baixa oferta de empregos. Em tais períodos, o papel social do empreendedorismo pode surgir como alternativa de se evitar um mal maior para a população e a economia de uma forma geral. 
Em conclusão sobre o objetivo desse artigo - analisar como a maior presença do empreendedorismo por oportunidade na taxa de atividade empreendedora (TEA) afeta o desenvolvimento econômico dos países, - pode-se dizer que, com base nos dados da pesquisa GEM de 2006 a 2010, o empreendedorismo por oportunidade estudado atua positivamente no desenvolvimento econômico dos países. Portanto, segundo esta pesquisa, quanto maior for a presença do empreendedorismo por oportunidade na taxa total TEA, maior será o desenvolvimento econômico. Pela sua natureza exploratória, os resultados encontrados não levam a uma conclusão definitiva, mas contribuem para melhor compreender as nuances do empreendedorismo.

Este trabalho apresenta algumas implicações para definições de políticas institucionais para o empreendedorismo. A formação de empreendedores com habilidades e conhecimento para perceber, analisar e colocar em prática uma oportunidade poderá render bons resultados no panorama econômico e social dos países e regiões. Novas oportunidades de investimentos para o mercado financeiro podem surgir com o início de novos serviços ou produtos lançados no mercado.

Incentivos fiscais e infraestrutura para empreendedores iniciantes em projetos inovadores também podem contribuir para a propagação do empreendedorismo por oportunidade. $\mathrm{O}$ aprofundamento dessa abordagem de estudo interessa aos agentes financeiros na medida em que, de uma forma ou de outra, o empreendedorismo envolve risco. Portanto, incentivar uma gama de negócios em que existe mais probabilidade de crescimento econômico tende a aumentar os resultados econômicos também. Por fim, sugere-se que os dados da pesquisa
GEM podem ser mais explorados, comparando-os com outros fatores importantes para o desenvolvimento dos países.

\section{OPPORTUNITY OR NECESSITY? A STUDY OF THE IMPACT OF ENTREPRENEURSHIP ON ECONOMIC DEVELOPMENT}

\section{SUMMARY}

This article discusses the importance of entrepreneurship for economic growth and development, as inspired by the motivation of starting one business, whether by necessity or by chance. In this context, the theoretical framework presents the concepts of entrepreneurship, economic development and the relationship between these phenomena. The variables used in this study were the ratio of rates of entrepreneurship by chance and by necessity disseminated by the Global Entrepreneurship Monitor (GEM) and the human development index (HDI) as released by the United Nations Development Program (UNDP). The data were collected in the survey reports on GEM and human development report (HDR). The studied period was from the year 2006 to 2010. Simple regression analysis was used to assess the behavior between the two variables. The results indicated that there is a moderate positive relationship between the two variables and that entrepreneurship by chance is more beneficial to the economic development of the countries, although the entrepreneurship by necessity may have its relevance as an alternative to unemployment.

Keywords: Entrepreneurship. Opportunity. Need. Economic Development. 


\section{REFERÊNCIAS}

ACS, Z. J. How Is Entrepreneurship good for economic growth? Innovations: technology, governance, globalization, v. 1, p. 97-107, 2006.

ACS, Z. J.; STOREY, D. J. Introduction: entrepreneurship and economic development. Regional Studies, v. 38, p. 871-877, nov. 2004.

BARROS, A. A.; PEREIRA, C. M. M. A. Empreendedorismo e crescimento econômico: uma análise empírica. Revista de Administração Contemporânea - RAC, v. 12, n. 4 , p. $975-993,2008$.

BERLUNG, K.; JOHANSSON, A. W. Constructions of entrepreneurship: a discourse analysis of academic publications. Journal of Enterprising Communities, v. 1, n. 1, p. 77-102, 2007.

BONACIN, C. A. G.; CUNHA, J. A. C. da; CORREAA, H. L. Mortalidade dos empreendimentos de micro e pequenas empresas: causas e aprendizagem. Revista Gestão e Regionalidade, v. 25, n. 74, maio. /ago. 2009.

BRASIL. Programa das Nações Unidas para o Desenvolvimento. Relatório do Desenvolvimento Humano 2010. 2010. Disponível em $<$ http://www.pnud.org.br $>$. Acesso em: 5 jan. 2012.
BRATU, A.; CORNESCU, V.; DRUICA, E. The role of the necessity and the opportunity entrepreneurship in economic development. Annals of Faculty of Economics, v.2, issue 1, p. 242-245, 2009.

CARRÃO, A. M. R.; JOHNSON, G. F.; MONTEBELO, M. I. L. A Influência do Grau de Escolaridade do Pequeno Empresário Sobre Sua Percepção de Negócio. REAd, 56. ed., v. 13 , n. 2, p. 1-25, mai./ ago., 2007.

CARREE, M. A.; THURIK, A. R. The impact of entrepreneurship on economic growth. In: AUDRESTCH, D. B.; ACS, Z. J. (Eds.). Handbook of Entrepreneurship research.. Cambridge: Cambridge University Publishers, 2003. p. 86-110.

CASSON, M. The Entrepreneur. TotowaNJ: Barnes \& Noble Books, 1982.

Entrepreneurship: theory, networks, history. Massachusetts: Edward Elgar Publishing, 2010.

CORRAR, L. J.; PAULO, E.; DIAS FILHO, J. M. Análise multivariada: para cursos de administração, ciências contábeis e economia. São Paulo: Atlas, 2011.

CORRÊA, V. S.; VALE, G. M. V. A dimensão das motivações empreendedoras: uma investigação retrospectiva. Pretexto, v. 14, n. 4, p. 11-28, 2013. 
CUNHA, S. K. da et al. O Sistema Nacional de inovação e a ação empreendedora no Brasil. Revista de Administração e Contabilidade da Unisinos, v. 6, n. 2, p. 120137, maio/ago. 2009.

DEGEN, R.J. O empreendedor: empreender como opção de carreira. São Paulo: Pearson Prentice Hall, 2009.

DOMINGUINHOS, P.; PEREIRA, R.; SILVEIRA, R. Processo de criação de empresas: um fenómeno colectivo ancorado no capital humano e social. Revista Portuguesa e Brasileira de Gestão, v.6. n.3, p. 89-93, jul./set. 2007.

DORNELAS, J.C.A. Empreendedorismo: transformando ideias em negócios. 3. ed. Rio de Janeiro: Elsevier, 2008.

DORNELAS, J.; TIMMONS, J. A.; SPINELLI, S. Criação de novos negócios: empreendedorismo para o século 21. São Paulo: Elsevier, 2010. Adaptação da $8^{\mathrm{a}}$ edição americana.

FERNADES, D. V. D. H.; SANTOS, C. P. dos. Orientação empreendedora: um estudo sobre as consequências do empreendedorismo nas organizações. RAE- Eletrônica, v. 7, n. 1, Art. 6, jan./jun. 2008.

FILION, L. J. Empreendedorismo: empreendedores e proprietários-gerentes de pequenos negócios. Revista de Administração, v. 34, n. 2, p. 05-28, 1999c.
FONTENELE, R. E. S. Empreendedorismo, competitividade e crescimento econômico: evidências empíricas. Revista de Administração Contemporânea, Curitiba, v. 14, n. 6, art. 6, p. 1094-1112, nov./dez. 2010.

FONTENELE, R. E. S.; MOURA, H. J.; LEOCADIO, A. L. Capital humano, empreendedorismo e desenvolvimento: evidências empíricas nos municípios do Ceará. Revista de Administração Mackenzie, São Paulo, v. 12, n. 5, set./out. 2011.

FOO, M.-D. D., Emotions and entrepreneurial opportunity evaluation. Entrepreneurship Theory \& Practice. 16 Mar. 2009. Disponível em:<http://ssrn.com/abstract $=1360905>$. Acesso em: 07 jan. 2012.

GLOBAL ENTREPRENEURSHIP MONITOR. Empreendedorismo no Brasil: pesquisa completa. Curitiba: IBQP, SEBRAE, SENAI, SESI, UFPR, 2010.

HAIR JR., J. F et al. Fundamentos de métodos de pesquisa em administração. Tradução de Lene Ribeiro. Porto Alegre: Bookman, 2005.

HISRICH, R. D.; PETERS, M. P.; SHEPHERD, D. A. Empreendedorismo. 7. ed. Porto Alegre: Bookman, 2009.

LUECKE, R. Ferramentas para empreendedores: ferramentas e técnicas para desenvolver seus negócios. Tradução de Ryta Vinagre. 3. ed. Rio de Janeiro: Record, 2009. 
MACHADO, J. G. R.; PAMPLONA, J. B. A ONU e o desenvolvimento econômico: uma interpretação das bases teóricas da atuação do PNUD. Economia e Sociedade, Campinas, v. 17, n. 1 (32), p. 53-84, abr. 2008.

MACIEL, C. O. Comportamento empreendedor e capacidade organizacionais: hierarquização e mensuração de seus efeitos no desempenho de empresas de pequeno porte. Revista Alcance, v. 16, n. 1, p. 26-44, jan./abr. 2009.

MARTES, A. C. B. Weber e Schumpeter: a ação econômica do empreendedor. Revista de Economia Política, v. 30, n. 2(118), p. 254-270, abr./jun. 2010.

MURPHY, P. J.; LIAO, J.; WELSCH, H. P.A conceptual history of entrepreneurial thought. Journal of Management History, v. 12, n. 1, p. 12-35, 2006.

OLIVEIRA, G. B. Uma discussão sobre o conceito de desenvolvimento. Revista FAE, Curitiba, v. 5, n. 2, p. 37-48, maio/ ago. 2002.

PINTO, C. O. F.; RUPPENTHAL, J. E. Empreendedorismo e a dinâmica do emprego no Brasil. G\&DR,v. 10, n. 2, p. 75-98, 2014.

ROCHA, E. L. C et al. Ensino de empreendedorismo nos cursos presenciais de graduação em administração em Fortaleza: um estudo dos conteúdos e instrumentos pedagógicos. Revista Administração: Ensino e Pesquisa (RAEP), v. 12, p. 393-414, 2011.

SALIMATH, M. S.; CULLEN, J. B. Formal and informal institutional effects on entrepreunership: a syntheses of nation-level research. International Journal of Organizational Analysis, v. 18, n. 3, p. 358-385, 2010.

SARFATI, G. Estágios de desenvolvimento econômico e políticas públicas de empreendedorismo e de micro, pequenas e médias empresas (MPMEs) em perspectiva comparada: os casos do Brasil, do Canadá, do Chile, da Irlanda e da Itália. Revista de Administração Pública - RAP, v. 47, n. 1, p. $25-48,2013$.

SCHUMPETER, J. A. A teoria do desenvolvimento econômico. São Paulo: Abril Cultural, 1982.

SHANE, S.; VENKATARAMAN, S. The promise of entrepreneurship as a field of research. The Academic of Management Review, v. 25, n. 1, p. 217-226, 2000.

SOUZA, E. C. L.; LOPEZ JR, G. S. . Empreendedorismo e desenvolvimento: uma relação em aberto. Revista de Administração e Inovação, São Paulo, v. 8, n. 3, p.120-140, jul./set. 2011. 
TANG, L.; KOVEOS, P. E. Venture entrepreneurship, inovation entrepreunership, and economic growth. Journal of Developmental Entrepreneurship, v. 9, n. 2, Aug. 2004.

VALE, G. V.; WILKINSON, J.; AMÂNCIO, R. Empreendedorismo, inovação e redes: uma nova abordagem. RAE-eletrônica, v. 7, n. 1, art. 7, jan./jun. 2008.

VERGARA, S. C. Projetos e relatórios de pesquisa em administração. 10. ed. São Paulo: [s.n], 2009. 